\title{
The changing pattern of acute respiratory distress syndrome over time: a comparison of two periods
}

\author{
Charalampos Pierrakos and Jean-Louis Vincent
}

ABSTRACT: This study aimed to assess whether patterns and outcomes of acute respiratory distress syndrome (ARDS) have changed due to improvements in mechanical ventilation techniques and support of critically ill patients, by comparing patients from two different periods in the same hospital.

We reviewed data from all patients with a diagnosis of ARDS (according to American-European Consensus Conference criteria) who were treated in our multidisciplinary department of intensive care (Erasme Hospital, Brussels) between January 2006 and April 2009 (group B, $n=210$ ) and compared them with our previously reported data (January 1993 to February 1995) (group A, $n=129$ ).

The prevalence of ARDS has decreased (from 2.5\% in group $A$ to $1.7 \%$ in group $B, p<0.001$ ). ARDS patients are now older and sepsis-related ARDS is more common. Multiple transfusion and trauma are less common causes of ARDS than in the past. Intensive care unit length of stay among survivors is shorter ( $13 \pm 9$ versus $17 \pm 17$ days, $p=0.025)$, and there was a trend to lower mortality rates in the more recent cohort $(46 \%$ versus $52 \%, p=0.158)$. Multiple organ failure (MOF) was the most common cause of death in both periods.

The pattern of ARDS has changed over time in our department. Patients with ARDS are now older and more severely ill. Sepsis-related ARDS is more frequent whereas trauma-related and/or transfusion-related ARDS has decreased. MOF still represents the most frequent cause of death.

KEYWORDS: Mortality, multiple organ failure, refractory hypoxaemia, sepsis

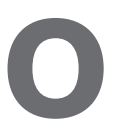
ver the past decade, several new treatment strategies for acute respiratory distress syndrome (ARDS) have been introduced and there have been improvements in mechanical ventilation techniques and in general support of critically ill patients. So-called protective mechanical ventilation with low tidal volumes and relatively high levels of positive end-expiratory pressure (PEEP), and more conservative fluid management may not only have improved lung function and resulted in better outcomes [1-3], but they may also have altered the type of patient who develops ARDS. A possible change in the characteristics of patients with ARDS is important, as new therapies or a different use of already existing therapies may be needed. Characterising these changes may also help in the design of clinical trials of potential new therapeutic interventions.

The aim of this study was to assess and describe any changes in the characteristics of patients with ARDS over time by comparing patients from two different periods in the same hospital. By studying two periods in the same unit, we reduced the possible impact of differences in unit structure, number of intensive care unit (ICU) beds, ICU admission/ discharge structure, staffing patterns and training, as these did not change significantly over time.

\section{METHODS}

The study was conducted in a 34-bed multidisciplinary Department of Intensive Care at Erasme Hospital, Brussels. We reviewed data from patients treated for ARDS from January 2006 to April 2009 (group B) and compared them with data from patients treated for ARDS from January 1993 to February 1995 (group A) [4]. In both studies, ARDS was defined according to the AmericanEuropean Consensus Conference (AECC) definition [5]: 1) respiratory failure of acute onset; 2) arterial oxygen tension $\left(\mathrm{Pa}_{\mathrm{a}} \mathrm{O}_{2}\right)$ /inspiratory oxygen fraction $\left(\mathrm{FIO}_{2}\right)$ ratio $<200 \mathrm{mmHg}$, regardless of the level of PEEP; 3) bilateral diffuse infiltrates on frontal chest radiograph; 4) a pulmonary artery balloon-occluded pressure (PAOP) of $<18 \mathrm{mmHg}$ or no clinical evidence of congestive heart failure.

\section{AFFILIATIONS}

Dept of Intensive Care, Erasme Hospital, Université Libre de Bruxelles, Brussels, Belgium.

\section{CORRESPONDENCE}

\section{J.-L. Vincent}

Dept of Intensive Care Erasme University Hospital Route de Lennik 808 B-1070 Brussels Belgium E-mail: jlvincen@ulb.ac.be

Received: July 292011 Accepted after revision: Jan 102012 First published online: Feb 092012 
During both time periods, patients were treated according to existing guidelines; no specific therapeutic algorithm was used. We collected the following data for each patient with ARDS in the two study groups: demographic information; length of stay in the ICU; causes of ARDS; clinical and laboratory data concerning organ failure. The main ICU admission category was recorded as medical, surgical, or nonsurgical trauma. In ICU nonsurvivors, the causes of death were recorded. In both study groups, a pulmonary source of infection was defined as the presence of new or changing infiltrates on chest radiograph, sputum or bronchoalveolar lavage fluid with leukocytes, and pathogenic organism on Gram-stain and/or cultures. Sepsis was defined as documented infection accompanied by systemic manifestations of an inflammatory response to infection [6]. Septic shock was defined as sepsis with a systolic blood pressure $<90 \mathrm{mmHg}$ or mean arterial pressure $<70 \mathrm{mmHg}$ in the absence of an aetiology other than sepsis and which persisted despite adequate fluid resuscitation [6]. Refractory hypoxia was defined by a $\mathrm{Pa}_{1} \mathrm{O}_{2}<60 \mathrm{mmHg}$ during mechanical ventilation under an $\mathrm{FIO}_{2}>90 \%$ (regardless of the PEEP) before the agonal period and not secondary to cardiovascular collapse. Multiple transfusion was said to be a cause of ARDS when ARDS occurred within $24 \mathrm{~h}$ of transfusion of more than 2 units of packed red cells, with no other obvious precipitating factor. Organ system failure was defined by the following criteria: 1) renal failure by a blood creatinine concentration $>1.5 \mathrm{mg} \cdot \mathrm{dL}^{-1}$, or oliguria (urine output $<0.5 \mathrm{~mL} \cdot \mathrm{kg}^{-1} \cdot \mathrm{h}^{-1}$ ); 2) cardiovascular failure by the need for vasopressor agents (norepinephrine, epinephrine or dopamine); 3) coagulation failure by a platelet count of $<60,000$ platelets $\cdot \mathrm{mm}^{-3}$ and/or activated partial thromboplastin time $>1.5$ times the control value; 4) neurologic dysfunction by a Glasgow Coma Score $<8$ (estimated in sedated patients); 5) hepatic failure by total bilirubin $>5 \mathrm{mg} \cdot \mathrm{dL}^{-1}$ in the absence of haemolysis. Multiple organ failure (MOF) was defined as the coexistence of three or more such organ dysfunctions.
Data were analysed by unpaired t-test, Chi-squared test and Fisher's exact test. Differences were considered statistically significant at a $\mathrm{p}$-value $<0.05$.

\section{RESULTS}

The total number of ICU admissions increased over time to reach 3,000 admissions per year in the recent period, but the distribution of medical/surgical patients remained close to $50 \%$, with a similar case-mix in the two time periods. The more recent study group (group B) included 210 patients with ARDS while the earlier study group (A) included 129 ARDS patients. Group B patients with ARDS were older and were more likely to have a medical diagnosis than those in group A (table 1). Cardiovascular and renal failure were the most frequent types of associated organ dysfunctions in the two study groups, but both occurred more frequently in patients of Group B. Despite these differences, mortality rates in the two groups were similar (96 out of $210(46 \%)$ versus 67 out of $129(52 \%), p=0.158$, OR $0.7,95 \%$ CI $0.5-1.2)$. The time to death was also similar in the two periods (fig. 1). In both groups, medical patients had higher mortality rates than surgical or trauma patients (fig. 2), and in the medical patients, there was a significant decrease in mortality in the recent study group compared to the earlier group ( $50 \%$ versus $67 \%, \mathrm{p}=0.04$, OR $0.4,95 \%$ CI $0.2-0.9$ ). The length of ICU stay of survivors was shorter in the more recent period (table 1).

Patients with ARDS represented $1.7 \%$ of all ICU admissions in group B compared to $2.5 \%$ in group A $(p<0.01)$ (table 1$)$. The prevalence of ARDS in surgical patients decreased significantly over time from $3.0 \%$ to $1.0 \%(\mathrm{p}<0.01)$; the prevalence of ARDS in medical patients in the two cohorts was not significantly different $(1.9 \%$ versus $2.3 \%, \mathrm{p}=0.141)$ (table 1$)$. The causes of ARDS in the two study groups are shown in table 2. Sepsis was the most common cause of ARDS in both study groups but was more frequent in the more recent period. In contrast, there was

TABLE 1 Demographic characteristics of the patients in the two studies

\begin{tabular}{|c|c|c|c|}
\hline & Group A 1993-1995 & Group B 2006-2009 & p-value \\
\hline Total patients admitted during the period $n$ & 5086 & 12559 & \\
\hline Patients with ARDS $\mathbf{n}$ & 129 & 210 & \\
\hline Prevalence of ARDS \% & 2.5 & 1.7 & $<0.01$ \\
\hline Age of ARDS patients yrs & $52 \pm 13$ & $58 \pm 15$ & $<0.01$ \\
\hline Medical patients $\mathrm{n}$ (\% of ARDS patients) & $49(38)$ & $146(69)$ & $<0.01$ \\
\hline Prevalence of ARDS in medical patients \% & 1.9 & 2.3 & 0.14 \\
\hline Surgical patients n (\% of ARDS patients) & $61(47)$ & $50(24)$ & $<0.01$ \\
\hline Trauma patients $\mathrm{n}$ (\% of ARDS patients) & $19(15)$ & $14(7)$ & $<0.02$ \\
\hline Prevalence of ARDS in surgical/trauma patients \% & 3 & 1 & $<0.01$ \\
\hline ARDS patients with cardiovascular failure $\mathbf{n}(\%)$ & $54(42)$ & $124(59)$ & $<0.01$ \\
\hline ARDS patients with acute renal failure $n$ (\%) & $56(42)$ & $115(55)$ & $<0.03$ \\
\hline \multicolumn{4}{|l|}{ ICU stay days } \\
\hline Survivors & $17 \pm 17$ & $13 \pm 9$ & $<0.03$ \\
\hline Nonsurvivors & $13 \pm 24$ & $14 \pm 8$ & 0.58 \\
\hline ICU mortality \% & 52 & 46 & 0.16 \\
\hline
\end{tabular}

Data are presented as mean $\pm \mathrm{SD}$, unless otherwise indicated. ARDS: acute respiratory distress syndrome; ICU: intensive care unit. 


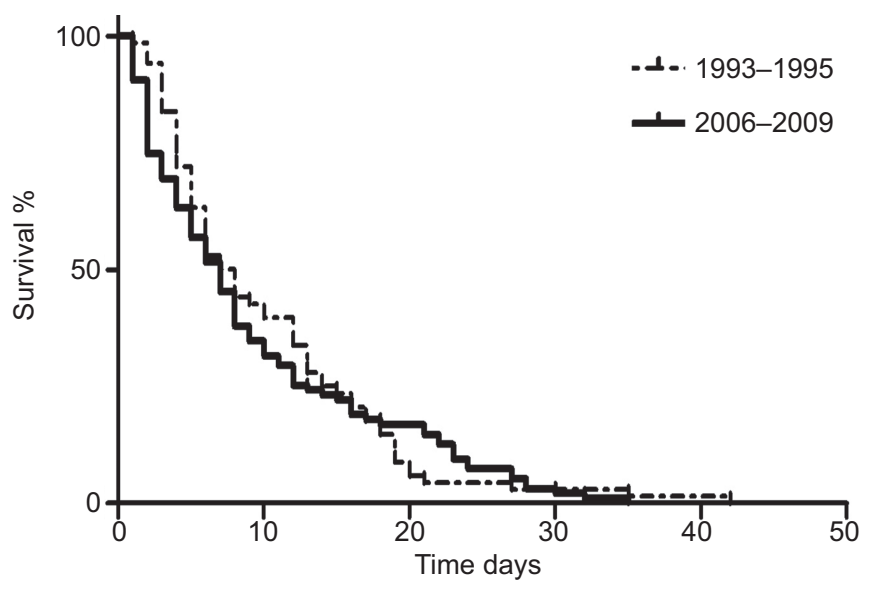

FIGURE 1. Time to death of nonsurvivors in the two cohorts. $p=0.687$.

a decrease in the incidence of ARDS secondary to postoperative shock, trauma or multiple transfusions.

The causes of death in the two time periods are shown in fig. 3. The most common cause of death in both studies was MOF, but especially in the more recent period. Refractory hypoxia was less common in the more recent than in the earlier study group ( $7 \%$ versus $16 \%, \mathrm{p}=0.06$ ). The mortality rate in patients with a large number of organ failures $(>4)$ was similarly large in both studies (fig. 4).

\section{DISCUSSION}

This study in a large multidisciplinary department of intensive care revealed an important change in the pattern of ARDS over time. There was a decrease in the prevalence of ARDS between the two periods, especially among surgical and trauma patients, with an increased contribution of sepsis as a cause, but a reduced contribution of trauma and transfusions. We also observed that MOF was an increasingly common cause of death whereas fewer patients died of refractory hypoxia.

ARDS was a relatively rare syndrome in both our groups of patients and our reported prevalence may seem lower than in

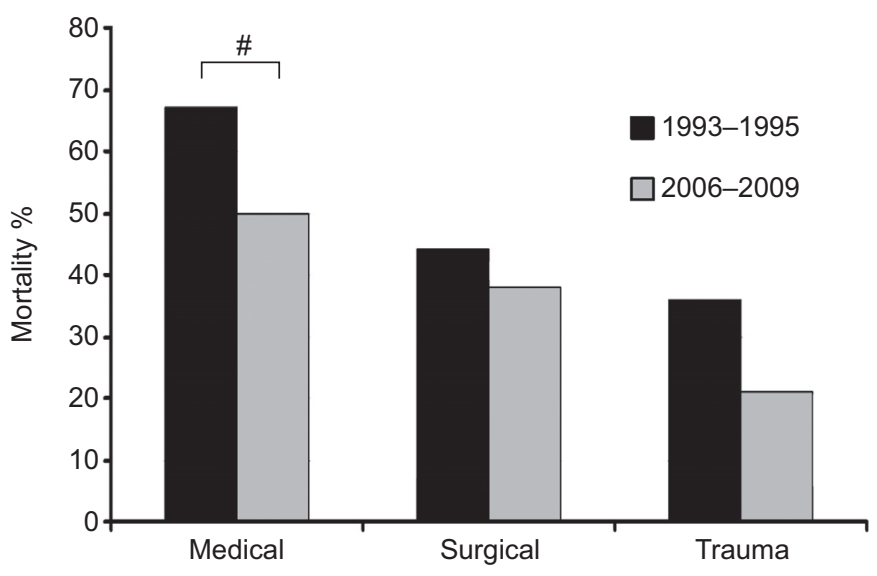

FIGURE 2. Intensive care unit mortality rates in the two cohorts for the different types of patient (medical, surgical or trauma). * : $p=0.04,2006-2009$ versus 1993-1995.

\begin{tabular}{lccc} 
TABLE 2 & $\begin{array}{c}\text { Causes of acute respiratory distress syndrome } \\
\text { (ARDS) in the two cohorts }\end{array}$ \\
& $\begin{array}{c}\text { Group A } \\
\mathbf{1 9 9 3 - 1 9 9 5}\end{array}$ & $\begin{array}{c}\text { Group B } \\
\mathbf{2 0 0 6 - 2 0 0 9}\end{array}$ & p-value \\
& $60(39)$ & $155(74)$ & $<0.01$ \\
\hline Sepsis & $18(14)$ & $72(34)$ & $<0.01$ \\
$\quad$ Pulmonary & $32(25)$ & $83(40)$ & $<0.01$ \\
$\quad$ Nonpulmonary & $30(23)$ & $20(9)$ & $<0.01$ \\
Post-operative shock & $18(14)$ & $11(5)$ & $<0.01$ \\
Trauma & $5(4)$ & $6(3)$ & 0.42 \\
Aspiration & $4(3)$ & $4(2)$ & 0.37 \\
Pancreatitis & $9(7)$ & $3(1)$ & $<0.01$ \\
Multiple transfusions & $8(6)$ & $3(1)$ & 0.01 \\
Neurogenic & $4(3)$ & $5(2)$ & 0.45 \\
Others & & & \\
\hline
\end{tabular}

Data are presented as $\mathrm{n}$ (\% of ARDS patients), unless otherwise stated.

some other studies, in which rates of ARDS have varied from $3 \%$ to $9 \%$ [7-10]. Obviously, the incidence of ARDS will vary according to the case-mix of patients treated in the different ICUs studied [10]. The decreased prevalence of ARDS was more notable in the surgical/trauma patients than in the medical patients, in accordance with other studies [11-13]. A strength of our study is the broad case-mix present in our mixed medicosurgical ICU, which currently admits about 3,000 patients per year with an equal number of medical and surgical patients. More importantly, other studies have usually combined patients with acute lung injury (ALI) and ARDS, which gives much higher overall incidence rates. We preferred not to include patients with ALI, as this diagnosis is more commonly missed [14] and is associated with lower mortality rates [7]. It is possible that the decrease in the prevalence of ARDS over time that we observed was balanced by an increase in the number of cases of the less severe ALI.

During the 10-yr period that separated our two study populations, there were several changes in the ways in which patients were managed in general in the ICU, which may have influenced the prevalence of and outcomes from ARDS, but these are difficult to quantify and generally occurred gradually. We have listed some possible changes in table 3. As in other institutions, we decreased tidal volumes and in general try to use more "gentle" ventilation. Other possible changes include prone positioning, which is now used in severe cases, and nitric oxide inhalation in life-threatening hypoxaemia, lesser use of sedation in mechanically ventilated patients, stricter control of blood glucose, earlier administration of enteral nutrition, and administration of activated protein $C$ in patients with severe sepsis with more than two organ failures. More restrictive blood transfusion strategies and better preparation of the transfused red blood cells may also have contributed to the decrease in the prevalence of ARDS, especially in trauma patients $[13,15,16]$. Importantly, it was not our aim to determine the individual effects of specific changes in management but rather to achieve a more global view of the possible combined influence of all these changes on patterns and outcomes of ARDS. Of note, there have been no major organisational changes in our department or the hospital 

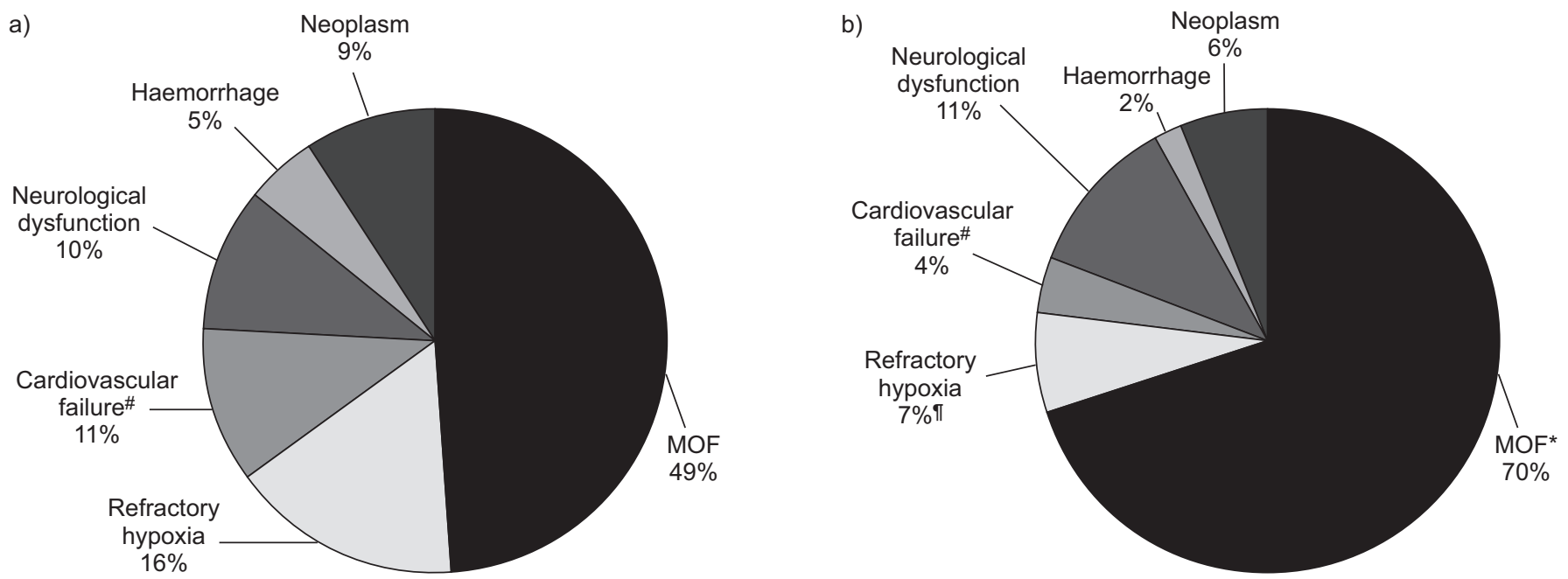

FIGURE 3. Causes of death a) 1993-1995 and b) 2006-2009. MOF: multiple organ failure. * : nonsecondary to refractory hypoxia. *: p<0.05, ": p=0.06, 2006-2009 versus 1993-1995.

during the 10-yr period that could have influenced admission/ discharge criteria or the types or origins of patients admitted.

Sepsis was the most common cause of ARDS, and was even more frequent in the recent cohort than in the earlier one. This observation is in agreement with the results of other studies which have also reported that sepsis is the most frequent cause of ARDS [17, 18]. Sepsis was more common in the recent cohort, but there was a larger ill-defined group of post-operative ARDS patients in the earlier study group, many of whom may have had sepsis. The incidence of ARDS secondary to multiple transfusions decreased significantly. However, it is impossible from our data to determine whether this was due to a reduction in the use of blood transfusions or better blood preservation in recent years as a result of leukoreduction and other factors.

The mean ICU length of stay in the survivors decreased. This observation is important as patients with ARDS consume significant healthcare resources in the ICU because of their long

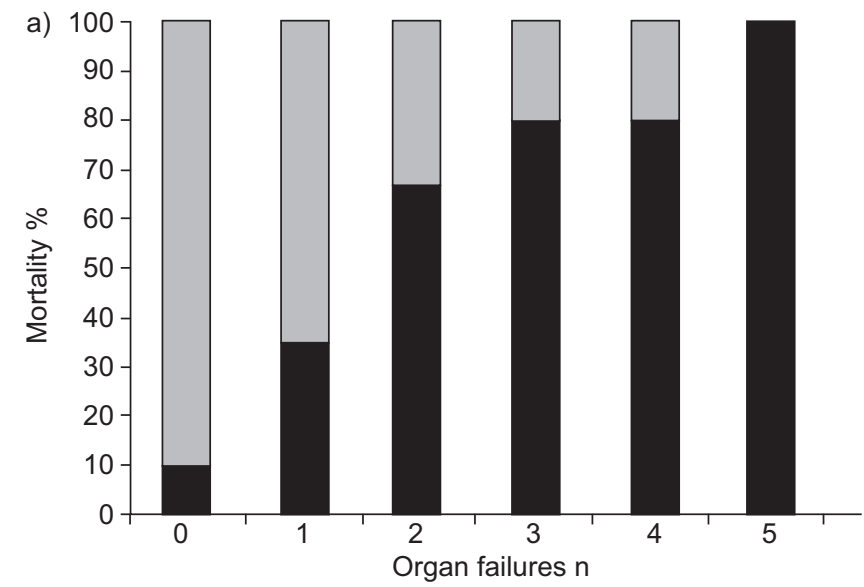

stay [19]. This reduction in length of stay may also be associated with a decrease in the occurrence of long-term complications, including the incidence of acquired polyneuromyopathy [20].

There are now considerable amounts of data suggesting a reduction in mortality rates from ARDS in recent years [1, 2126]. Several of these studies have evaluated the pattern of ARDS over time in the same institution or region [16, 21-28]. All these studies, except two [16, 25], reported a decrease in the mortality rate among ARDS patients over time. However, the majority of the studies were conducted at a period before or soon after the landmark publication of the ARDSnet study on the importance of limiting tidal volumes [29]. In four of the studies [23, 25, 26, 28], introduction of a lower tidal volume strategy is mentioned as a possible reason for the decrease in the mortality rate during the more recent period. In one study [25], where a comparison was made between cohorts of patients before and after 2000, only 66 patients were treated in the 20012003 period compared to 277 for the earlier 1993-2000 period. In

\section{Survivors \\ nonsurvivors}

b)

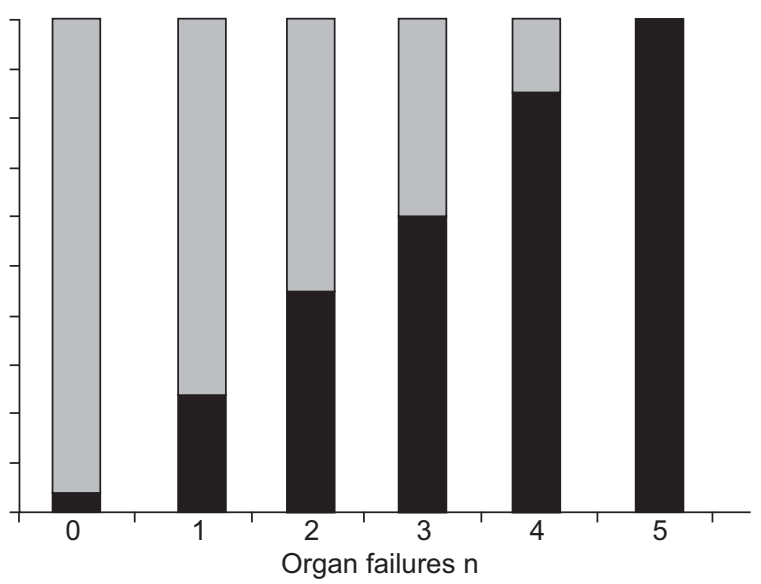

FIGURE 4. Intensive care unit mortality rates according to the number of organ failures other than lung. a) 1993-1995; b) 2006-2009. 
TABLE 3 Some key changes in the management of patients between the two study periods in our department

1993-1995

Ventilation with larger tidal volumes

Plateau pressure $<35 \mathrm{cmH}_{2} \mathrm{O}$

No nitric oxide administration

No use of prone position

Less strict control of blood glucose

Haemoglobin $<8-9 \mathrm{~g} \cdot \mathrm{dL}^{-1}$ as trigger for transfusion

No use of activated protein $C$

Physiotherapists available only during the daytime

Later administration of enteral nutrition

Sedation of patients with mechanical ventilation
2006-2009

\author{
Ventilation with low tidal volume (around $6 \mathrm{~mL} \cdot \mathrm{kg}^{-1} \cdot \mathrm{min}^{-1}$ ) \\ Plateau pressure $<30 \mathrm{cmH}_{2} \mathrm{O}$ \\ Nitric oxide administration in severe hypoxaemia \\ Prone position in severe cases \\ Stricter control of blood glucose \\ Haemoglobin $<7-8 \mathrm{~g} \cdot \mathrm{dL}^{-1}$ as trigger for transfusion \\ Use of activated protein $\mathrm{C}$ in patients with severe sepsis with more than one organ failure \\ Physiotherapists available $24 \mathrm{~h}$ \\ Early administration of enteral nutrition \\ Minimal sedation of patients
}

this study [25], there was no change in the mortality rate but the patients in the later period were sicker, as reflected by a higher APACHE II (Acute Physiology and Chronic Health Evaluation II) score and lower initial $\mathrm{Pa}_{\mathrm{a}} \mathrm{O}_{2} / \mathrm{FIO}_{2}$ ratio. Similar results were reported from a more recent study that evaluated patients from 2001 until 2008 [16]. In this study, the ARDS case fatality did not decrease over time, but the severity of illness of the patients increased. In our study, there was no statistically significant difference in the mortality rate between the two study groups as a whole, although mortality rates in medical patients were significantly lower in the recent cohort. Patients who develop ARDS today may be more severely ill, due in part to their older age and more comorbid conditions. We do not routinely measure severity indexes in our department, but the more recent ARDS population was somewhat older, more of the patients had cardiovascular and/or renal failure, and there was a higher percentage of medical patients; all elements expected to increase mortality rates $[27,30,31]$. Additionally, the number of survivors with failure of fewer than four organs was higher in the more recent population compared with surviving patients from the earlier period. Hence, there may have been some improvement in morbidity over time.

Refractory hypoxia, already uncommon as a cause of death in 1993-1995, is becoming even rarer. Although the differences did not quite reach statistical significance, this finding is compatible with an overall clinical impression in the critical care community. Previous studies have shown that refractory hypoxia is a more common cause of death in patients with ARDS secondary to pulmonary infection compared to other aetiologies [32-34]. Hence, the decrease in the incidence of refractory hypoxia found is even more impressive if we consider that in the more recent study more patients had ARDS secondary to pulmonary infection. Importantly, the present study was performed in the absence of epidemics. The frequency of refractory hypoxia as a cause of death in patients with ARDS secondary to H1N1 infection may be somewhat higher [35].

MOF was the leading cause of death in patients with ARDS in both study periods. Interestingly, there were no differences in the types of organ failure seen in our two groups of ARDS patients. The most frequent organ failures were cardiovascular failure and acute renal failure in both studies. Additionally in both cohorts, all patients with failure in five organs, in addition to respiratory failure, died, implying that the severity of organ dysfunction remains directly related to the risk of death. MOF may be the result of the same inflammatory response mechanisms that are involved in the pathogenesis of ARDS, and ventilation-induced inflammation may contribute to its development by its detrimental effects in other organs [36-40]. Interestingly, we found the contribution of MOF as a cause of death has increased over time. One explanation for this increase could be that the number of septic patients was higher in the recent cohort compared to the earlier one. If MOF is the leading cause of death rather than respiratory causes per se, this may explain why strategies that have focused primarily on improving respiratory function have failed to decrease mortality rates in patients with ARDS [41-43].

This study presents the experience of one centre, which can be seen as a limitation as it reduces the generalisability of the results. However, this may also be a strength as there were no changes in the number of ICU beds, admission/discharge criteria, staffing, policies related to end-of-life care, and general management principles between the two periods, which may influence results when comparing different centres. Interestingly two meta-analyses $[1,44]$ that evaluated the mortality of ARDS over time from studies conducted in different hospitals and countries produced conflicting results, mainly because of different methodologies [45]. Moreover, mortality rates in randomised controlled studies (RCTs) were generally lower than those in observational studies $(36 \%$ versus $44 \%$ ) [45], because of the large numbers of exclusion criteria in RCTs, limiting their real-life applicability. Consequently, we believe that the results of our study provide important information about the effects of the multiple new treatment strategies on the population of ARDS patients.

\section{Conclusions}

From our data, the pattern of ARDS has changed compared to several years ago. The prevalence of ARDS has decreased, especially among surgical and trauma patients. Sepsis remains the most common cause of ARDS, and is even more common than before. ICU length of stay in survivors has decreased and mortality rates may also have decreased slightly. Refractory hypoxia is an uncommon cause of death in ARDS and its contribution to mortality rates has decreased over time. MOF is the primary cause of death.

\section{STATEMENT OF INTEREST}

None declared. 


\section{REFERENCES}

1 Zambon M, Vincent JL. Mortality rates for patients with acute lung injury/ARDS have decreased over time. Chest 2008; 133: 1120-1127.

2 Matuschak GM, Lechner AJ. Acute lung injury and the acute respiratory distress syndrome: pathophysiology and treatment. Mo Med 2010; 107: 252-258.

3 Yilmaz M, Keegan MT, Iscimen R, et al. Toward the prevention of acute lung injury: protocol-guided limitation of large tidal volume ventilation and inappropriate transfusion. Crit Care Med 2007; 35: 1660-1666.

4 Ferring M, Vincent JL. Is outcome from ARDS related to the severity of respiratory failure? Eur Respir J 1997; 10: 1297-1300.

5 Bernard GR, Artigas A, Brigham KL, et al. The American-European Consensus Conference on ARDS. Definitions, mechanisms, relevant outcomes, and clinical trial coordination. Am J Respir Crit Care Med 1994; 149: 818-824.

6 Bone RC, Balk RA, Cerra FB, et al. Definitions for sepsis and organ failure and guidelines for the use of innovative therapies in sepsis. The ACCP/SCCM Consensus Conference Committee. American College of Chest Physicians/Society of Critical Care Medicine. Chest 1992; 101: 1644-1655.

7 Brun-Buisson C, Minelli C, Bertolini G, et al. Epidemiology and outcome of acute lung injury in European intensive care units. Results from the ALIVE study. Intensive Care Med 2004; 30: 51-61.

8 Wind J, Versteegt J, Twisk J, et al. Epidemiology of acute lung injury and acute respiratory distress syndrome in The Netherlands: a survey. Respir Med 2007; 101: 2091-2098.

9 Zilberberg MD, Carter C, Lefebvre P, et al. Red blood cell transfusions and the risk of acute respiratory distress syndrome among the critically ill: a cohort study. Crit Care 2007; 11: R63.

10 Rubenfeld GD, Herridge MS. Epidemiology and outcomes of acute lung injury. Chest 2007; 131: 554-562.

11 Plurad D, Martin M, Green D, et al. The decreasing incidence of late postraumatic acute respiratory distress syndrome: the potential role of lung protective ventilation and conservative transfusion practice. J Trauma 2007; 63: 1-7.

12 Aldrian S, Koenig F, Weninger $\mathrm{P}$, et al. Characteristics of polytrauma patients between 1992 and 2002: what is changing? Injury 2007; 38: 1059-1064.

13 Ciesla DJ, Moore EE, Johnson JL, et al. Decreased progression of postinjury lung dysfunction to the acute respiratory distress syndrome and multiple organ failure. Surgery 2006; 140: 640-647.

14 Goss CH, Brower RG, Hudson LD, et al. Incidence of acute lung injury in the United States. Crit Care Med 2003; 31: 1607-1611.

15 Chaiwat O, Lang JD, Vavilala MS, et al. Early packed red blood cell transfusion and acute respiratory distress syndrome after trauma. Anesthesiology 2009; 110: 351-360.

16 Li G, Malinchoc M, Cartin-Ceba R, et al. Eight-year trend of acute respiratory distress syndrome: a population-based study in Olmsted County, Minnesota. Am J Respir Crit Care Med 2011; 183 : 59-66.

17 Irish Critical Care Trials Group. Acute lung injury and the acute respiratory distress syndrome in Ireland: a prospective audit of epidemiology and management. Crit Care 2008; 12: R30.

18 Lu Y, Song Z, Zhou X, et al. A 12-month clinical survey of incidence and outcome of acute respiratory distress syndrome in Shanghai intensive care units. Intensive Care Med 2004; 30: 2197-2203.

19 Carson SS, Bach PB. The epidemiology and costs of chronic critical illness. Crit Care Clin 2002; 18: 461-476.

20 Garnacho-Montero J, Amaya-Villar R, Garcia-Garmendia JL, et al. Effect of critical illness polyneuropathy on the withdrawal from mechanical ventilation and the length of stay in septic patients. Crit Care Med 2005; 33: 349-354.
21 Milberg JA, Davis DR, Steinberg KP, et al. Improved survival of patients with acute respiratory distress syndrome (ARDS): 1983 1993. JAMA 1995; 273: 306-309.

22 Abel SJ, Finney SJ, Brett SJ, et al. Reduced mortality in association with the acute respiratory distress syndrome (ARDS). Thorax 1998; 53: 292-294.

23 Suchyta MR, Orme JF Jr, Morris AH. The changing face of organ failure in ARDS. Chest 2003; 124: 1871-1879.

24 Stapleton RD, Wang BM, Hudson LD, et al. Causes and timing of death in patients with ARDS. Chest 2005; 128: 525-532.

25 Eachempati SR, Hydo LJ, Shou J, et al. Outcomes of acute respiratory distress syndrome (ARDS) in elderly patients. J Trauma 2007; 63 344-350.

26 Rocco TR Jr, Reinert SE, Cioffi W, et al. A 9-year, single-institution, retrospective review of death rate and prognostic factors in adult respiratory distress syndrome. Ann Surg 2001; 233: 414-422.

27 Navarrete-Navarro P, Rodriguez A, Reynolds N, et al. Acute respiratory distress syndrome among trauma patients: trends in ICU mortality, risk factors, complications and resource utilization. Intensive Care Med 2001; 27: 1133-1140.

28 Jardin F, Fellahi JL, Beauchet A, et al. Improved prognosis of acute respiratory distress syndrome 15 years on. Intensive Care Med 1999; 25: 936-941.

29 The Acute Respiratory Distress Syndrome Network. Ventilation with lower tidal volumes as compared with traditional tidal volumes for acute lung injury and the acute respiratory distress syndrome. N Engl J Med 2000; 342: 1301-1308.

30 Suchyta MR, Clemmer TP, Elliott CG, et al. Increased mortality of older patients with acute respiratory distress syndrome. Chest 1997; 111: 1334-1339.

31 Hyers TM. Prediction of survival and mortality in patients with adult respiratory distress syndrome. New Horiz 1993; 1: 466-470.

32 Suchyta MR, Clemmer TP, Elliott CG, et al. The adult respiratory distress syndrome. A report of survival and modifying factors. Chest 1992; 101: 1074-1079.

33 Anzueto A, Baughman RP, Guntupalli KK, et al. Aerosolized surfactant in adults with sepsis-induced acute respiratory distress syndrome. Exosurf Acute Respiratory Distress Syndrome Sepsis Study Group. N Engl J Med 1996; 334: 1417-1421.

34 Taccone $\mathrm{P}$, Pesenti A, Latini $\mathrm{R}$, et al. Prone positioning in patients with moderate and severe acute respiratory distress syndrome: a randomized controlled trial. JAMA 2009; 302: 1977-1984.

35 Rello J, Rodriguez A, Ibanez $\mathrm{P}$, et al. Intensive care adult patients with severe respiratory failure caused by Influenza A (H1N1)v in Spain. Crit Care 2009; 13: R148.

36 Ranieri VM, Suter PM, Tortorella C, et al. Effect of mechanical ventilation on inflammatory mediators in patients with acute respiratory distress syndrome: a randomized controlled trial. JAMA 1999; 282: 54-61.

37 Ranieri VM, Giunta F, Suter PM, et al. Mechanical ventilation as a mediator of multisystem organ failure in acute respiratory distress syndrome. JAMA 2000; 284: 43-44.

38 Slutsky AS, Tremblay LN. Multiple system organ failure. Is mechanical ventilation a contributing factor? Am J Respir Crit Care Med 1998; 157: 1721-1725.

39 Pugin J, Dunn I, Jolliet P, et al. Activation of human macrophages by mechanical ventilation in vitro. Am J Physiol 1998; 275 L1040-L1050.

40 Moloney ED, Griffiths MJ. Protective ventilation of patients with acute respiratory distress syndrome. Br J Anaesth 2004; 92: 261-270

41 Adhikari NK, Burns KE, Friedrich JO, et al. Effect of nitric oxide on oxygenation and mortality in acute lung injury: systematic review and meta-analysis. BMJ 2007; 334: 779.

42 Mercat A, Richard JC, Vielle B, et al. Positive end-expiratory pressure setting in adults with acute lung injury and acute respiratory 
distress syndrome: a randomized controlled trial. JAMA 2008; 299: 646-655.

43 Fernandez R, Trenchs X, Klamburg J, et al. Prone positioning in acute respiratory distress syndrome: a multicenter randomized clinical trial. Intensive Care Med 2008; 34: 1487-1491.
44 Phua J, Badia JR, Adhikari NK, et al. Has mortality from acute respiratory distress syndrome decreased over time? A systematic review. Am J Respir Crit Care Med 2009; 179: 220-227.

45 Zambon M, Vincent JL. Are outcomes improving in patients with ARDS? Am J Respir Crit Care Med 2009; 180: 1158-1159. 